\title{
PERANCANGAN PROTOTIPE SISTEM KEAMANAN TANDA TERA UNTUK POMPA UKUR BBM
}

\author{
Shafira Salsabila Suri ${ }^{1}$, Fitri Rahmah ${ }^{2}$, Fitria Hidayanti ${ }^{3}$ \\ Teknik Fisika, Universitas Nasional ${ }^{1,2,3}$ \\ shafira.s.suri@gmail.com
}

Submitted March 10, 2021; Revised June 19, 2021; Accepted June 19, 2021

\begin{abstract}
Abstrak
Salah satu masalah yang kerap kali terjadi di bidang metrologi legal adalah kecurangan segel cap tanda tera (CTT). Penelitian ini berfokus pada kecurangan yang terjadi pada Alat Ukur Takar Timbang dan Perlengkapannya (UTTP) jenis pompa ukur (PU) BBM dimana terdapat kasus pelaku kecurangan membuka badan pelindung luar dari PU BBM dan memutus CTT yang melekat di badan ukur. Penelitian ini bertujuan untuk membuat sistem keamanan berupa pengunci tambahan yang akan diletakkan di luar badan ukur PU BBM agar hanya pemilik akses yang bisa masuk. Prinsip kerja dari sistem ini menggunakan RFID untuk autentikasi, solenoid door lock sebagai pengunci dan SIM800L untuk mengirimkan SMS notifikasi. Hasil yang didapatkan dari penelitian ini adalah persentase keberhasilan RFID terhadap solenoid door lock untuk tap akses yang sesuai adalah sebesar $93 \%$ dengan rata rata waktu respon selama 0,78 detik sedangkan untuk tap akses yang tidak sesuai adalah sebesar $100 \%$ dengan rata rata waktu respon selama 0,72 detik. Lalu, persentase keberhasilan RFID terhadap SIM800L untuk tap akses yang sesuai adalah sebesar $87 \%$ dengan rata rata waktu respon selama 20,87 detik sedangkan untuk tap akses yang tidak sesuai adalah sebesar $93 \%$ dengan rata rata waktu respon selama 18,22 detik.
\end{abstract}

Kata Kunci : Tanda Tera, RFID, Solenoid Door Lock, SIM800L

\begin{abstract}
One of the problems that often occur in the field of legal metrology is fraud of the metrology sign (CTT). This research focuses on the fraud that occurs in the Measuring Equipment and Equipment (UTTP) type of fuel measuring pump (PU) where there are cases of fraudsters opening the outer protective body of PU BBM and breaking the CTT attached to the measuring body. This study aims to create a security system in the form of an additional lock that will be placed outside the PU BBM measuring body so that only the owner can enter. The working principle of this system uses RFID for authentication, solenoid door lock as a lock and SIM800L for sending SMS notifications. The results obtained from this study are the percentage of success of RFID against the solenoid door lock for suitable access taps is $93 \%$ with an average response time of 0.78 seconds while for unsuitable access taps is $100 \%$ with an average response time during 0.72 seconds. Then, the success percentage of RFID against SIM800L for the appropriate access tap was $87 \%$ with an average response time of 20.87 seconds while for unsuitable access taps was $93 \%$ with an average response time of 18.22 seconds.
\end{abstract}

Key Words : Metrology Sign, RFID, Solenoid Door Lock, SIM800L

\section{PENDAHULUAN}

Metrologi merupakan ilmu ukur mengukur secara luas. Metrologi terdiri dari metrologi ilmiah, metrologi industri dan metrologi legal. Dari segi pelaksanaannya, metrologi industri dan metrologi ilmiah bersifat voluntary sedangkan metrologi legal bersifat mandatory. Metrologi legal bersifat mandatory karena merupakan metrologi yang mengelola satuan-satuan ukuran, metoda-metoda pengukuran dan alat-alat ukur, yang menyangkut persyaratan teknik dan peraturan berdasarkan undang-undang metrologi legal yang bertujuan melindungi 
kepentingan umum dalam hal kebenaran pengukuran [1].

Dalam hal ini, metrologi legal selalu berkaitan dengan proses tera, tera ulang, ijin tipe dan ijin tanda pabrik. Seluruh alat Ukur, Takar, Timbang dan Perlengkapannya (UTTP) yang berada dalam lingkup metrologi legal harus melalui proses tersebut. Dimana setiap alat UTTP harus melalui prosedur ijin tipe dan ijin tanda pabrik sebagai ijin edar UTTP luar negeri maupun dalam negeri, dan kemudian wajib ditera dan ditera ulang secara terjadwal [2].

Tidak jarang dan tidak sedikit produsen atau pedagang berusaha untuk melewatkan atau mencurangi proses tera dan tera ulang agar mendapat laba yang lebih banyak. Bahkan oknum yang curang berupaya membuat tanda tera palsu agar alat UTTP yang digunakan terlihat seperti sudah melalui prosedur peneraan saat diperiksa oleh petugas metrologi yang berwenang dalam hal ini yaitu penera, sehingga untuk mengurangi tindak kecurangan tersebut pihak penera menggunakan fungsi segel atau cap sebagai jaminan keabsahan alat UTTP telah dilakukan tera.

Disebutkan pada Kamus Besar Bahasa Indonesia, arti kata segel adalah tera dan cap. Dengan pengertian lain, segel difungsikan sebagai pengunci atau gembok yang biasa digunakan untuk memenuhi jaminan barang yang disegel masih dalam keadaan baru atau tidak bekas. Suatu barang yang sudah tidak bersegel menandakan bahwa barang tersebut telah digunakan oleh seseorang. Pada bidang metrologi legal, segel sangat berkaitan dengan jaminan atau keabsahan suatu alat ukur. Dimana segel dalam metrologi legal merupakan tanda bahwa alat UTTP telah ditera atau ditera ulang dalam bentuk Cap Tanda Tera (CTT). Setiap alat UTTP memiliki jangka waktu tertentu untuk melakukan tera ulang. Seperti contohnya Pompa Ukur Bahan Bakar Minyak (PU
BBM) pada Stasiun Pengisian Bahan Bakar Umum (SPBU) ditera ulang setiap 1 tahun. [3] PU BBM tersebut setelah ditera atau tera ulang harus diberi segel CTT agar tidak diubah atau dicurangi oleh oknum tertentu. Segel biasanya dirancang sedemikian rupa sehingga tidak mudah bagi orang lain yang tidak berhak untuk membukanya. Para penera Unit Metrologi Legal (UML) yang bertugas dalam kegiatan tera/tera ulang memiliki segel CTT untuk alat UTTP yang terbuat dari logam tertentu yang bentuk, dimensi, material dan kegunaannya diatur oleh menteri sesuai dengan jenis UTTP. Sebagai contoh, letak CTT dari PU BBM ini diletakkan di dekat badan ukur PU BBM yang memiliki fungsi mengatur besar kecilnya aliran volume BBM yang akan keluar dari nozzle. PU BBM harus benarbenar dalam pantauan petugas metrologi legal karena mengingat transaksi jual beli BBM yang tidak murah dan juga menyangkut tugas pokok dan fungsi seorang petugas metrologi legal yaitu melindungi kepentingan umum dalam hal kebenaran pengukuran.

Berdasarkan berita yang dilansir media online Bali Express, terdapat dua buah SPBU di Kabupaten Badung yang melakukan pelanggaran berupa perusakan kawat segel tanda jaminan di PU BBM [4]. Jika ada indikasi terbuka segelnya, dapat diduga adanya perubahan yang disengaja pada badan ukur sehingga meteran yang keluar tidak sesuai sehingga ketika dilakukan pengujian kebenaran kuantitasnya melebihi Batas Kesalahan yang Diizinkan (BKD) sesuai ketetapan yaitu 0,5 persen. Selama 2019 Direktorat Jenderal Perlindungan Konsumen dan Tertib Niaga (Dirjen PKTN) melakukan inspeksi dadakan ke SPBU di 33 kabupaten/kota dari delapan provinsi. Yakni Riau, Lampung, Jawa Barat, Jawa Tengah, Jawa Timur, Bali, Maluku Utara, dan Gorontalo. Selain di Bali, ditemukan juga SPBU yang terindikasi melakukan 
kecurangan, yakni di Medan, Gorontalo, dan Batam dengan jumlah total sekitar 14 SPBU. Selain itu, terdapat juga jenis kecurangan seperti menyelipkan alat tambahan pada PU BBM berupa rangkaian elektronik printed circuit board (PCB) yang dapat mengontrol aliran dari ruangan kantor hanya dengan memutar switch seperti yang diberitakan oleh media online Tribun Bali [5].

Oleh karena itu, penulis beranggapan bahwa dibutuhkan sebuah sistem proteksi keabsahan segel CTT yang dapat sekaligus melindungi badan ukur tempat melekatnya segel CTT pada PU BBM. Beberapa penelitian sistem proteksi sudah banyak dikerjakan dengan beragam macam sensor dan kegunaan. Berdasarkan sebuah penelitian berjudul "RFID Based Security System Using Arduino Module", radio frequency identification (RFID) dapat difungsikan sebagai sistem autentifikasi dan juga sistem proteksi. Sistem kontrol akses berbasis RFID dinyatakan lebih aman dan merespons dengan cepat dibandingkan dengan sistem lain seperti sistem biometrik contohnya fingerprint. Keuntungan dari sistem RFID adalah dapat bekerja tanpa saling berhadapan dan tanpa kontak. Dengan menggunakan Arduino, akses mudah dan pekerjaan dapat dilakukan dengan sangat cepat. Sistem proteksi yang dirancang juga dapat mengubah fungsi di Arduino sesuai kebutuhan seperti meningkatkan jangkauan akses untuk membaca tag RFID sehingga dapat lebih mudah digunakan dan dengan hasil yang sangat akurat. Maka dari itu penelitian ini dapat bermanfaat untuk memberikan sistem proteksi dan implementasi aplikasi kontrol akses [6]. Sistem lainnya yang memanfaatkan RFID adalah sistem keamanan pada rumah pintar. Penelitian berjudul "Security Framework for RFID-based Applications in Smart Home Environment" memperkenalkan beberapa skenario contoh praktis yang berkaitan dengan aplikasi berbasis RFID di lingkungan rumah pintar [7] Selain memanfaatkan tag RFID, penelitian ini pun memanfaatkan PIN yang tersimpan di dalam mikrokontroler sehingga selain melakukan tap user juga memasukan PIN agar lebih aman. Pintu akan terbuka jika nomor ID RFID dan PIN dikenali oleh sistem.[8] Kemudian terdapat penelitian keamanan pintu rumah yang tag RFID nya bisa menggunakan e-KTP[9] dan penelitian sistem keamanan pintu rumah yang hasil monitoring sistem keamanannya diteruskan ke SMS, email, dan real time berdasarkan Internet of Things. [10]

\section{METODE PENELITIAN}

Perancangan sistem pengaman tanda tera ini terdiri dari perangkat keras yang aktifitasnya dikendalikan oleh perangkat lunak sehingga semua sistem dapat saling berintegrasi. Sistem yang dirancang dapat bekerja secara otomatis bila mendapatkan masukan dari luar. Secara blok diagram penulis membagi menjadi beberapa bagian yang dapat dilihat pada Gambar 1 berikut.

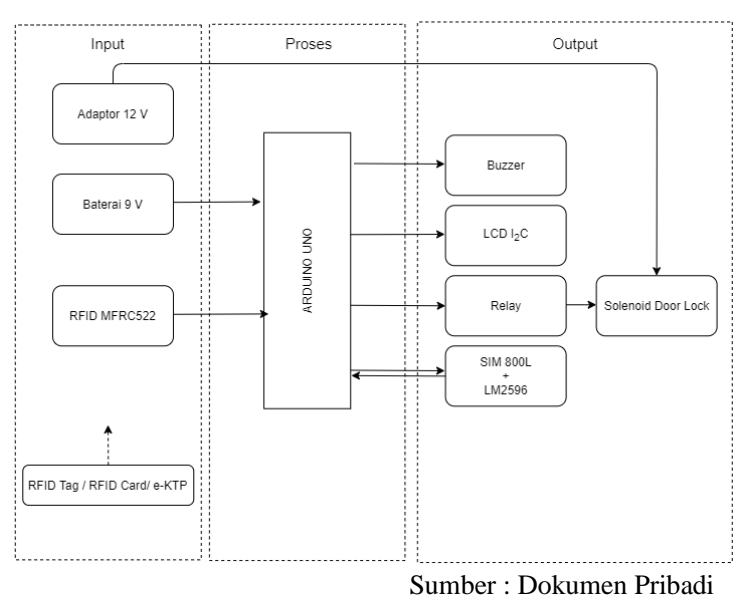

Gambar 1. Diagram Blok

Pada Gambar 1 dijelaskan sumber tegangan berasal dari input baterai $9 \mathrm{~V}$ untuk arduino dan adaptor $12 \mathrm{~V}$ untuk dapat mengaktifkan relay dan solenoid door lock. Lalu RFID sebagai input untuk diproses dalam mikrokontroler Arduino UNO. Kemudian solenoid door lock, 
buzzer, LCD dan SIM800L berfungsi sebagai output untuk sistem pengunci tambahan, alarm, indikator display dan notifikasi akses RFID ke pegawai berhak.

Desain hardware alat yang akan dirancang pada sistem keamanan segel cap tanda tera ini terbuat dari kayu berukuran $35 \times 25 \times$ $20 \mathrm{~cm}$. Bentuk desain tampak depan hardware dapat dilihat pada Gambar 2.

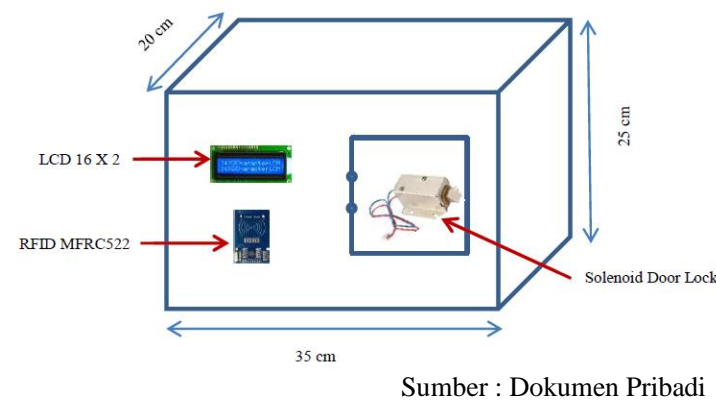

Gambar 2. Desain Alat

Rangkaian sistem keamanan segel CTT dalam penelitian ini akan ditempatkan di dalam maket badan luar pelindung pompa ukur BBM yang berbentuk kotak mirip pintu loker dengan material kayu sebelum diimplementasikan langsung ke badan luar pelindung pompa ukur BBM yang sesungguhnya di lapangan. Berikut pada Gambar 3 ditunjukkan desain rangkaian elektronika.

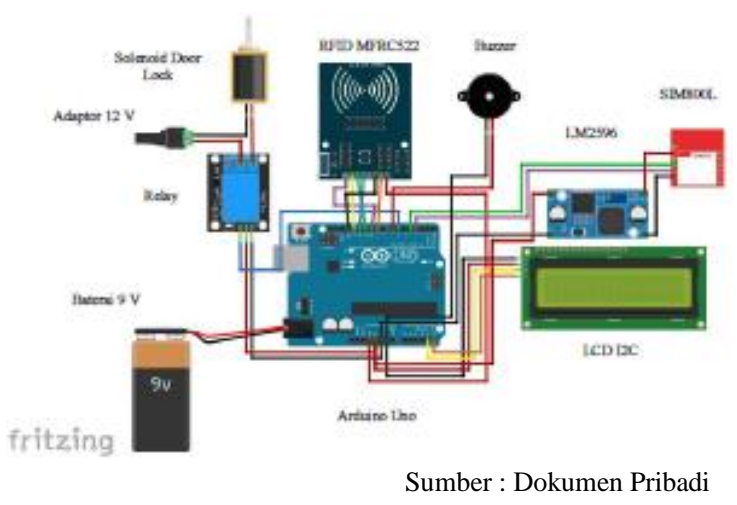

Gambar 3. Desain Rangkaian Elektronika

Prinsip kerja dari Sistem Keamanan Tanda Tera untuk Pompa Ukur BBM yaitu ketika tag RFID, card RFID atau e-KTP terbaca oleh reader RFID MFRC522 dan sesuai dengan program serta fungsi yang telah diatur oleh sistem maka kunci solenoid akan terbuka dan mendapatkan akses ke dalam Pompa Ukur BBM. Namun apabila tap akses yang digunakan salah atau tidak sesuai dengan yang ada di database maka mikrokontroler akan membunyikan alarm dari buzzer dan mengirimkan pesan singkat atau SMS kepada petugas metrologi legal yang berwenang dalam hal ini adalah penera dan pengawas metrologi daerah setempat bahwa ada usaha masuk paksa ke dalam PU BBM. Harapannya dengan adanya sistem ini, pelaku usaha SPBU tidak bisa sembarang dalam mengubah alat justir yang ada pada badan ukur PU BBM dan tidak berusaha mencurangi segel cap tanda tera yang tertempel di badan ukur PU BBM. Berikut pada Gambar 4 ditunjukkan diagram alir perancangan sistem secara keseluruhan.

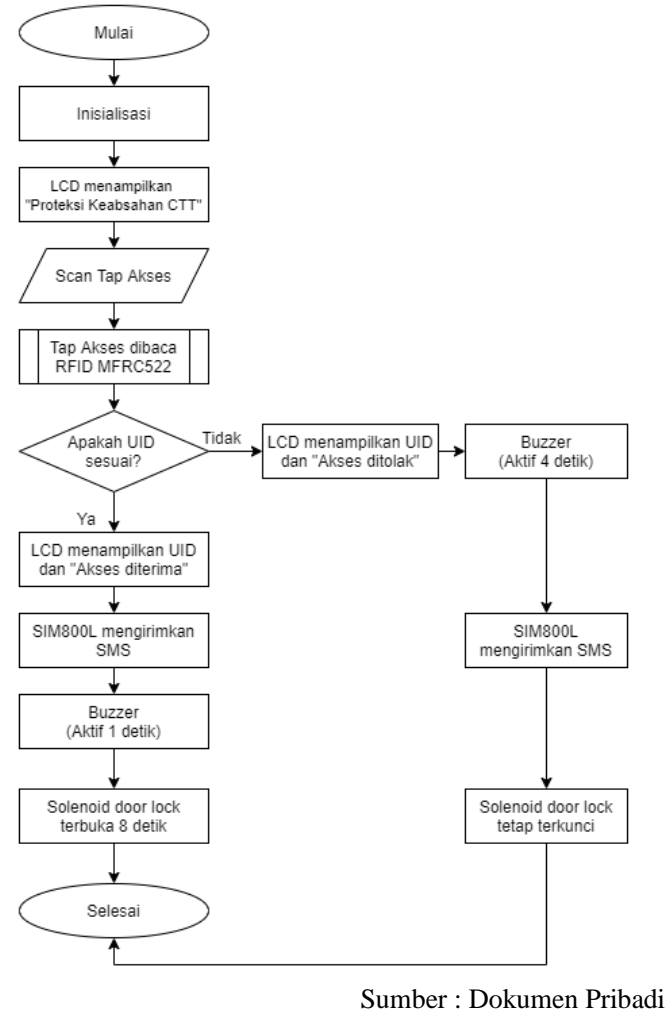

\section{Gambar 4. Diagram Alir Perancangan Sistem}

Setelah dilakukan perancangan, dilakukan pula pengujian. Pengujian keseluruhan 
sistem bertujuan untuk mengetahui keberhasilan dari sistem keamanan yang telah dirancang mulai dari keberhasilan reader RFID dalam membaca tap akses, lalu LCD menampilkan keterangan dari tap akses, kemudian indikator bunyi dari buzzer serta waktu yang diperlukan modul SIM800L untuk sebuah aktuator sistem keamanan yakni solenoid door lock terbuka dan tertutup untuk mengirimkan SMS berisikan data tanda tera yang terdiri dari tanggal kegiatan tera ulang, pegawai berhak serta posisi dari PU BBM. Pengujian keseluruhan sistem akan menghasilkan beberapa data berupa persentase keberhasilan tiap komponen, serta waktu respon antara RFID dan Solenoid Door Lock serta SIM800L. Berikut pada Gambar 5 ditunjukkan ilustrasi pengujian keseluruhan sistem.

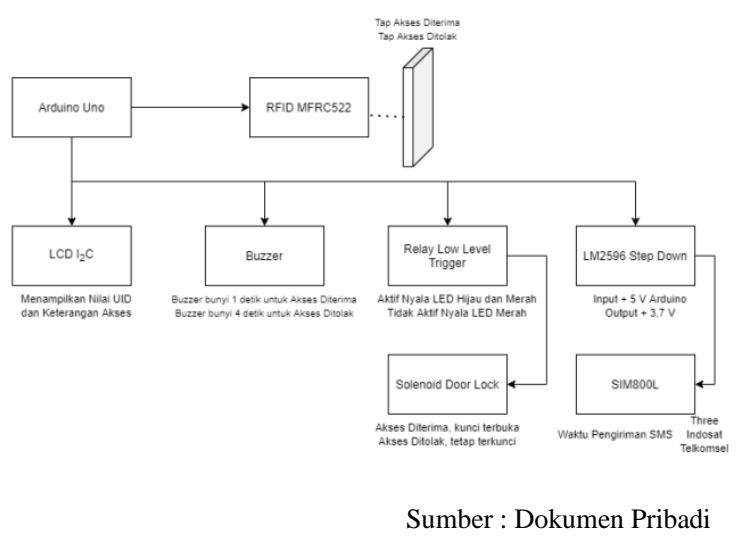

Gambar 5. Ilustrasi Pengujian Keseluruhan Sistem

\section{HASIL DAN PEMBAHASAN}

Hasil pembuatan sistem keamanan tanda tera dapat dilihat pada Gambar 6 di bawah ini.

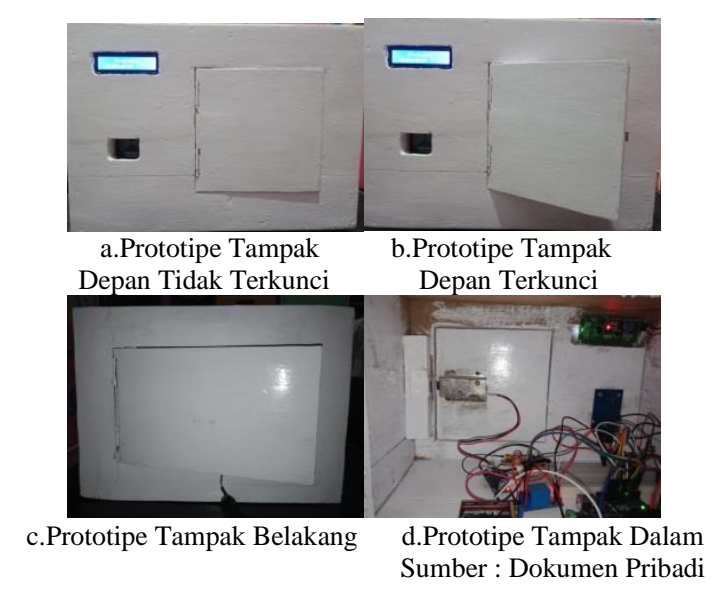

\section{Gambar 6. Hasil Pembuatan Sistem Keamanan Tanda Tera}

Setelah semua komponen disatukan dan dipasang pada maket pelindung luar maka pengujian keseluruhan dapat dilakukan. Pertama aktifkan catu daya rangkaian arduino dengan menghubungkannya ke baterai dan adaptor $12 \mathrm{~V}$ ke solenoid door lock. Saat rangkaian aktif, mode pengaman langsung pada kondisi aktif. Kondisi pintu dibiarkan pada posisi terkunci. LCD menampilkan "Proteksi Keabsahan CTT" yang menandakan bahwa sistem telah siap. Setelah itu tap akses dapat digunakan dan discan ke reader RFID. Pada saat tap akses tidak sesuai dengan yang telah terdaftar pada program, buzzer akan langsung aktif (berbunyi) selama 4 detik dan posisi solenoid door lock akan tetap terkunci kemudian pegawai berhak akan menerima SMS dari nomor yang digunakan pada SIM800L dengan pesan "Akses Masuk Ditolak. Pengaman Badan Luar PU BBM X. Ditera ulang tanggal 01 Jan 21 oleh IR". Sebaliknya, pada saat tap akses sesuai dengan yang telah terdaftar pada program buzzer akan langsung aktif (berbunyi) selama 1 detik dan posisi solenoid door lock akan terbuka kemudian pegawai berhak akan menerima SMS dari nomor yang digunakan pada SIM800L dengan pesan "Akses Masuk Diterima. Pengaman Badan Luar PU BBM X. Ditera ulang tanggal 01 Jan 21 oleh IR". Dengan demikian pengujian ini memberikan hasil 
yang cukup memuaskan karena semua komponen bekerja dengan baik. Dan dapat dikatakan bahwa sistem telah bekerja secara keseluruhan dengan baik dan benar sesuai kondisi yang diinginkan.

Untuk hasil pengujian keseluruhan sistem detailnya dapat dilihat pada bagian Lampiran dan berikut di bawah ini merupakan hasil persentase keberhasilan pengujian keseluruhan sistem yang dilakukan sebanyak 30 kali pengujian menggunakan tap akses sesuai dan tidak sesuai serta provider telkomsel sebagai provider pengirim dengan pertimbangan dari hasil pengujian SIM800L yang didapatkan sebelumnya bahwa provider telkomsel memiliki respon waktu yang lebih cepat di antara 2 provider lainnya.

Tabel 1. Persentase Keberhasilan Pengujian Sistem

\begin{tabular}{|c|c|c|c|c|}
\hline \multirow[b]{2}{*}{$\begin{array}{l}\text { Keterangan } \\
\text { Tap Akses }\end{array}$} & \multicolumn{4}{|c|}{ Persentase Keberhasilan } \\
\hline & $\begin{array}{c}\text { RFID } \\
\text { MFRC522 }\end{array}$ & LCD Buzzer Relay & $\begin{array}{l}\text { Solenoid } \\
\text { Door } \\
\text { Lock }\end{array}$ & $\begin{array}{c}\text { SIM800 } \\
\text { L }\end{array}$ \\
\hline Sesuai & $100 \%$ & $100 \% 100 \% 100 \%$ & $93 \%$ & $87 \%$ \\
\hline $\begin{array}{l}\text { Tidak } \\
\text { Sesuai }\end{array}$ & $100 \%$ & $100 \% 100 \% 100 \%$ & $100 \%$ & $93 \%$ \\
\hline
\end{tabular}

Dari hasil pengujian keseluruhan sistem di atas didapatkan persentase keberhasilan yang sangat baik untuk masing-masing komponen dimana dari 30 kali percobaan untuk tap akses sesuai program, RFID MFRC522 sebagai reader, LCD sebagai indikator display, buzzer sebagai indikator bunyi, serta relay sebagai saklar penghubung ke solenoid door lock dapat bekerja secara optimal yaitu dengan tingkat keberhasilan $100 \%$. Namun, untuk solenoid door lock terdapat 2 kali kegagalan dalam melakukan fungsinya membuka pelindung luar pada percobaan ke 7 dan 16. Jika dianalisis dari relay, pada percobaan ke 7 dan 16 relay dapat bekerja sesuai dengan fungsinya dimana relay mengalirkan arus dan LED aktif nyala merah dan hijau tetapi kondisi solenoid door lock tetap terkunci. Hal ini dapat terjadi dimungkinkan karena goyangnya kabel penghubung antara adaptor $12 \mathrm{~V}$ dengan solenoid door lock. Kemudian pada SIM800L terdapat 4 kali kegagalan dalam mengirim SMS notifikasi ke pegawai berhak yaitu pada percobaan ke 9, 10, 14 dan 22. Hal tersebut dapat dikarenakan gangguan sinyal yang kurang stabil dimana modul SIM800L tidak dapat menerima perintah yang sesuai.

Selanjutnya, untuk tap akses yang tidak sesuai program, RFID MFRC522 sebagai reader, LCD sebagai indikator display, buzzer sebagai indikator bunyi, serta relay sebagai saklar penghubung ke solenoid door lock dapat bekerja secara optimal yaitu dengan tingkat keberhasilan 100\%. Namun, pada SIM800L terdapat 2 kali kegagalan dalam mengirim SMS notifikasi ke pegawai berhak yaitu pada percobaan ke 7 dan 20. Hal tersebut dapat dikarenakan gangguan sinyal yang kurang stabil dimana modul SIM800L tidak dapat menerima perintah yang sesuai.

Kemudian, dilakukan juga pengujian respon waktu pembacaan tap akses terhadap RFID, LCD, buzzer dan solenoid door lock serta tap akses terhadap SIM800L sebanyak 30 kali percobaan bersamaan dengan pengujian keberhasilan sebelumnya. Pengujian ini dilakukan menggunakan stopwatch yang dihitung sesaat setelah tap akses didekatkan ke RFID reader untuk mengetahui respon waktu minimal, maksimal, rata rata dan standar deviasi dari masing masing tap akses untuk merespon dan melaksanakan fungsinya. Data pengujian respon waktu secara rinci dapat dilihat pada Tabel 2 dan Tabel 3. 
Tabel 2. Data Pengujian Waktu Respon Tap Akses Sesuai

\begin{tabular}{|c|c|c|}
\hline $\begin{array}{c}\text { Pengujian } \\
\mathrm{Ke}\end{array}$ & $\begin{array}{l}\text { Waktu Respon } \\
\text { RFID (s) }\end{array}$ & $\begin{array}{l}\text { Waktu Respon } \\
\text { SIM800L (s) }\end{array}$ \\
\hline 1 & 0,7 & 20,6 \\
\hline 2 & 0,9 & 19,2 \\
\hline 3 & 0,8 & 19,9 \\
\hline 4 & 1 & 19,8 \\
\hline 5 & 0,7 & 19,3 \\
\hline 6 & 0,6 & 20,8 \\
\hline 7 & - & 24,6 \\
\hline 8 & 0,8 & 20,3 \\
\hline 9 & 0,9 & - \\
\hline 10 & 0,7 & - \\
\hline 11 & 0,8 & 18,6 \\
\hline 12 & 0,8 & 20,2 \\
\hline 13 & 0,7 & 19,8 \\
\hline 14 & 0,9 & - \\
\hline 15 & 0,8 & 19,1 \\
\hline 16 & - & 19,4 \\
\hline 17 & 0,7 & 20,6 \\
\hline 18 & 0,9 & 18,6 \\
\hline 19 & 0,7 & 26,7 \\
\hline 20 & 0,7 & 35,2 \\
\hline 21 & 0,8 & 20,4 \\
\hline 22 & 0,6 & - \\
\hline 23 & 0,7 & 19,7 \\
\hline 24 & 0,8 & 16,8 \\
\hline 25 & 0,9 & 23,5 \\
\hline 26 & 0,8 & 21,8 \\
\hline 27 & 0,8 & 19,4 \\
\hline 28 & 0,7 & 16,4 \\
\hline 29 & 0,9 & 19,3 \\
\hline 30 & 0,8 & 22,6 \\
\hline
\end{tabular}

Tabel 3. Data Pengujian Waktu Respon Tap Akses Tidak Sesuai

\begin{tabular}{|c|c|c|}
\hline $\begin{array}{l}\text { Pengujian } \\
\mathrm{Ke}\end{array}$ & $\begin{array}{c}\text { Waktu Respon } \\
\text { RFID (s) }\end{array}$ & $\begin{array}{l}\text { Waktu Respon } \\
\text { SIM800L (s) }\end{array}$ \\
\hline 1 & 0,8 & 17,5 \\
\hline 2 & 0,6 & 17,3 \\
\hline 3 & 0,7 & 18,3 \\
\hline 4 & 0,8 & 17,1 \\
\hline 5 & 0,7 & 17,2 \\
\hline 6 & 0,6 & 16,9 \\
\hline 7 & 0,7 & - \\
\hline 8 & 0,6 & 19,7 \\
\hline 9 & 0,8 & 15,4 \\
\hline 10 & 0,7 & 18,6 \\
\hline 11 & 0,6 & 19,2 \\
\hline 12 & 0,7 & 20,2 \\
\hline 13 & 0,7 & 19,5 \\
\hline 14 & 0,6 & 17,9 \\
\hline 15 & 0,8 & 18,3 \\
\hline 16 & 0,9 & 18,7 \\
\hline 17 & 0,7 & 20,4 \\
\hline 18 & 0,8 & 18,4 \\
\hline 19 & 0,7 & 23,1 \\
\hline 20 & 0,6 & - \\
\hline 21 & 0,8 & 17,7 \\
\hline 22 & 0,7 & 18,5 \\
\hline 23 & 0,7 & 16,3 \\
\hline 24 & 0,8 & 15,9 \\
\hline 25 & 0,9 & 17,4 \\
\hline 26 & 0,6 & 21,8 \\
\hline 27 & 0,7 & 18,3 \\
\hline 28 & 0,7 & 16,9 \\
\hline 29 & 0,8 & 18,5 \\
\hline 30 & 0,8 & 15,2 \\
\hline
\end{tabular}

Berdasarkan 30 data pengujian dari masing masing jenis tap akses yaitu sesuai dan tidak sesuai di atas, didapatkan waktu respon maksimal, minimal, rata-rata dan standar deviasi yang ditunjukkan pada pada Tabel 4. 
Tabel 4. Waktu Respon Pengujian Keseluruhan Sistem

\begin{tabular}{|c|c|c|c|c|}
\hline \multirow{2}{*}{$\begin{array}{c}\text { Ket } \\
\text { Waktu } \\
\text { Respon }\end{array}$} & \multicolumn{2}{|c|}{$\begin{array}{c}\text { Waktu Respon Tap } \\
\text { Akses Sesuai } \\
\text { Terhadap (s) }\end{array}$} & \multicolumn{2}{|c|}{$\begin{array}{c}\text { Waktu Respon Tap } \\
\text { Akses Tidak Sesuai } \\
\text { Terhadap (s) }\end{array}$} \\
\hline & $\begin{array}{l}\text { LCD, } \\
\text { Buzzer, } \\
\text { Solenoid } \\
\text { Door } \\
\text { Lock } \\
\end{array}$ & SIM800L & $\begin{array}{c}\text { RFID, } \\
\text { Buzzer, } \\
\text { Solenoid } \\
\text { Door Lock }\end{array}$ & SIM800L \\
\hline Minimal & 0,6 & 16,4 & 0,6 & 15,2 \\
\hline Maksimal & 1 & 35,2 & 0,9 & 23,1 \\
\hline $\begin{array}{l}\text { Rata- } \\
\text { rata }\end{array}$ & 0,78 & 20,87 & 0,72 & 18,22 \\
\hline $\begin{array}{l}\text { Standar } \\
\text { deviasi }\end{array}$ & 0,098 & 3,643 & 0,089 & 1,774 \\
\hline
\end{tabular}

Dari hasil pengujian respon waktu, didapatkan grafik sebagai berikut:

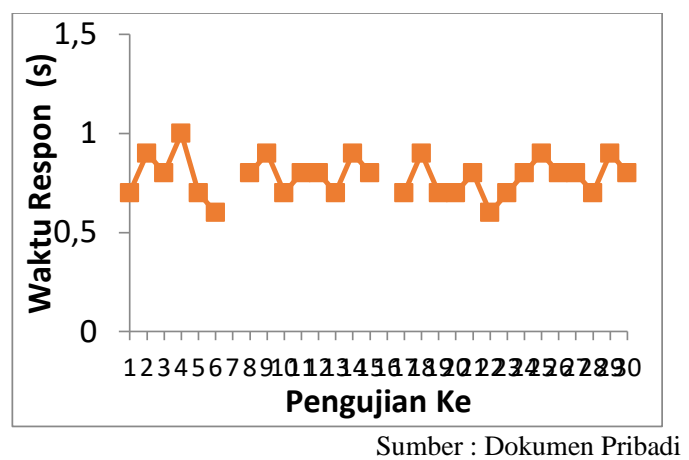

Gambar 7. Grafik Pengujian Respon Waktu RFID Tap Akses Sesuai

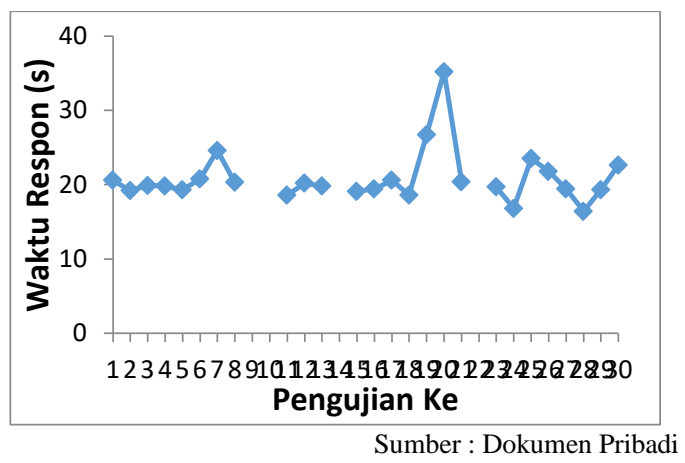

Gambar 8. Grafik Pengujian Respon Waktu SIM800L Tap Akses Sesuai

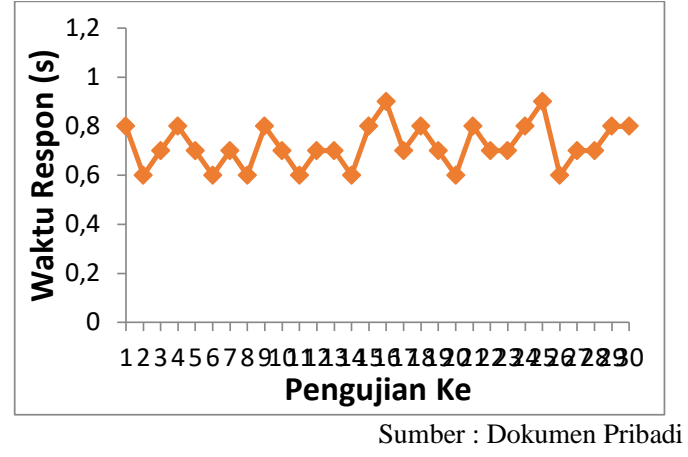

Gambar 9. Grafik Pengujian Respon Waktu RFID Tap Akses Tidak Sesuai

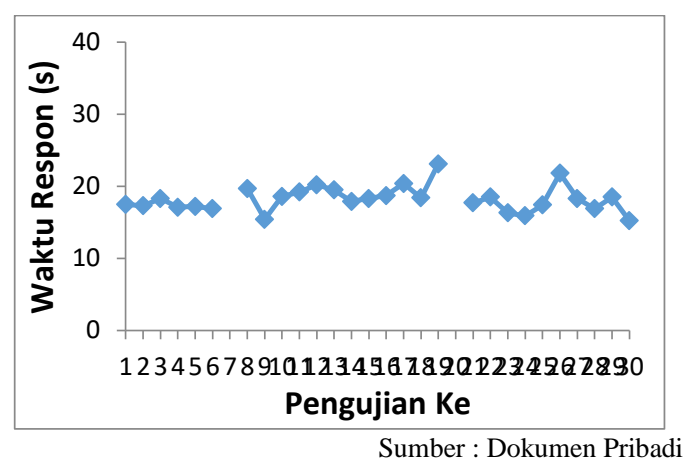

Gambar 12. Grafik Pengujian Respon Waktu SIM800L Tap Akses Tidak Sesuail

Dari tabel dan grafik di atas dapat dilihat untuk waktu respon dari RFID membaca tap akses dan melanjutkan fungsinya ke LCD, buzzer, dan solenoid door lock berkisar di rentang waktu 0,6 hingga 1 detik. Untuk tap akses yang sesuai, rata rata respon waktunya cenderung lebih lambat 0,06 detik. Hal ini disebabkan fungsi komponen yang dilakukan berdasarkan tap akses sesuai lebih banyak termasuk membuka solenoid door lock. Untuk waktu respon minimal RFID selama 0,6 detik pada tap akses sesuai dan tidak sesuai, lalu waktu respon maksimal RFID 1 detik pada tap akses sesuai dan 0,9 detik pada tap akses tidak sesuai. Didapatkan nilai standar deviasi yang kecil yaitu 0,098 pada tap akses sesuai dan 0,089 pada tap akses tidak sesuai.

Sedangkan pengujian respon waktu SIM800L dalam mengirimkan SMS pada tap akses sesuai didapatkan selisih rata-rata 
waktu respon 2,65 detik lebih lambat dibandingkan tap akses tidak sesuai. Untuk waktu respon maksimal pada tap akses sesuai adalah 35,2 detik sedangkan untuk tap akses tidak sesuai adalah 23,1 detik. Hal ini juga dipengaruhi dari sinyal yang ditangkap oleh modul SIM800L sehingga menyebabkan variasi data yang luas. Didapatkan nilai standar deviasi yang lebih besar dibandingkan standar deviasi pengujian respon waktu RFID yaitu 3,643 pada tap akses sesuai dan 1,774 pada tap akses tidak sesuai. Hal tersebut dikarenakan semakin besar standar deviasinya maka semakin beragam nilai nilainya sebaliknya semakin kecil standar deviasinya maka semakin serupa nilai nilainya.

\section{SIMPULAN}

Hasil akhir yang didapatkan dari penelitian ini adalah persentase keberhasilan RFID terhadap solenoid door lock untuk tap akses yang sesuai adalah sebesar 93\% dengan rata rata waktu respon selama 0,78 detik sedangkan untuk tap akses yang tidak sesuai adalah sebesar $100 \%$ dengan rata rata waktu respon selama 0,72 detik. Kemudian persentase keberhasilan RFID terhadap SIM800L untuk tap akses yang sesuai adalah sebesar $87 \%$ dengan rata rata waktu respon selama 20,87 detik sedangkan untuk tap akses yang tidak sesuai adalah sebesar $93 \%$ dengan rata rata waktu respon selama 18,22 detik.

\section{DAFTAR PUSTAKA}

[1] B. N. R. Indonesia, Undang-Undang Republik Indonesia Nomor 2 Tahun 1981 tentang Metrologi Legal. Indonesia, 1981.

[2] B. N. R. Indonesia, Peraturan Menteri Perdagangan Republik Indonesia Nomor 67 Tahun 2018 tentang Alat-alat Ukur, Takar, Timbang, dan Perlengkapannya Yang Wajib Ditera dan Ditera
Ulang. Indonesia, 2018.

[3] B. N. R. Indonesia, Peraturan Menteri Perdagangan Republik Indonesia Nomor 68 Tahun 2018 tentang Tera dan Tera Ulang Alatalat Ukur, Takar, Timbang, dan Perlengkapannya. Indonesia, 2018, p. 6.

[4] N. Suarna, "Rusak Kawat Segel, Empat SPBU di Bali Diduga Lakukan Kecurangan," Bali Express, Bali, 2019.

[5] Z. N. Arifin, "4 SPBU di Bali Diduga Curangi Pompa Ukur BBM, Pemilik Beralasan Rusak," Tribun Bali, Bali, 2019.

[6] A. Khare, J. Yadav, and D. Shardhana, "RFID Based Security System Using Arduino Module," Int. J. Res. Eng. Sci. Manag., vol. 3, no. 5, pp. 695-697, 2020, [Online]. Available:

https://www.ijresm.com/articles/rfid -based-security-system-usingarduino-module/.

[7] D. M. Konidala, D.-Y. Kim, C.-Y. Yeun, and B.-C. Lee, "Security Framework for RFID-based Applications in Smart Home Environment," J. Inf. Process. Syst., vol. 7, no. 1, pp. 111-120, 2011, doi: 10.3745/jips.2011.7.1.111.

[8] G. K. Verma and P. Tripathi, "A Digital Security System with Door Lock System Using RFID Technology," Int. J. Comput. Appl., vol. 5, no. 11 , pp. $6-8,2010$, doi: 10.5120/957-1334.

[9] M. Andriansyah, M. Subali, I. Purwanto, S. A. Irianto, and R. A. Pramono, "E-KTP as The Basis of Home Security System Using Arduino UNO," in 2017 4th International Conference on Computer Applications and Information Processing Technology (CAIPT), 2017, pp. 1-5, doi: 10.1109/CAIPT.2017.8320693. 
[10] K. Shingala and J. Patel, "Automatic Home Appliances and Security of Smart Home with RFID , SMS , Email and Real Time Algorithm Based on IOT," Int. Res. J. Eng. Technol., vol. 4, no. 4, pp. 19581964, 2017. 